\title{
Rearrangement of a 3-acyloxyamino-1,5-diketone into enamine and pyrrole: a mechanistic study
}

\author{
Cornelia Uncuta, *a Emeric Bartha, ${ }^{\mathrm{a}}$ Catalin I. Tanase, ${ }^{\mathrm{a}}$ Anca Tanase, ${ }^{\mathrm{a}}$ Oana Costan, \\ Mihaela Ciuca, ${ }^{a}$ Nicolas Vanthuyne, ${ }^{b}$ and Christian Roussel ${ }^{\text {b }}$ \\ ${ }^{a}$ Center of Organic Chemistry “C.D. Nenitzescu”,Spl. Independentei 202B, 35-108, \\ 060023 Bucharest, Romania \\ ${ }^{b}$ University Paul Cézanne-Aix-Marseille III, Ave. Escadrille Normandie Niemen, \\ 13397 Marseille Cedex 20, France \\ E-mail :christian.roussel@univ.u-3mrs.fr; cuncuta@cco.ro
}

\section{Dedicated to Professor Alexandru T. Balaban on the occasion of his $75^{\text {th }}$ birthday}

\begin{abstract}
The paper reports on the diversity of products obtained from a 3-acyloxyamino-1,5 diketone in reaction with bases, the distribution of products being correlated with the nature of the base and the solvent. Like other derivatives of $\beta$-hydroxyamino ketones, this compound reacts to form a 2 acylaziridine. Unusually, however, the aziridine undergoes ring-opening with carbon-carbon bond breaking to yield a $\beta$-ketoenaminone as isolable product. A minor path occurring with carbon-nitrogen bond breaking gives an $\alpha$-acylpyrrole. In a further reaction the ketoenaminone forms a dimer which is characterized by X-ray crystallography.
\end{abstract}

Keywords: Aziridine rearrangement, aziridine-ring enlargement, captodative radical, dimerization, heterocycles

\section{Introduction}

We reported recently on a new synthon generated in several steps from 2,6-di-tert-butyl-4methylpyrylium perchlorate and hydroxylamine, namely 5-isoxazolidinol $\mathbf{1}$. The occurrence of ring-chain tautomers of $\mathbf{1}$ has been demonstrated by regioselective acylation with carboxylic anhydrides which gave 1,3,5-trisubstituted 3-acyloxyamino-1,5-diketones $\mathbf{2}{ }^{1}$

This present paper reports on the rearrangement of the derivatives $\mathbf{2}$, under basic conditions, into the enamino-diketone 4 and the $\alpha$-keto pyrrole derivative $\mathbf{5}$. We found that the reaction occurred through the intermediate aziridine diketone 3 (Scheme 1). 
<smiles>CC1(CC(=O)C(C)(C)C)C[C@](O)(C(C)(C)C)ON1</smiles>

1

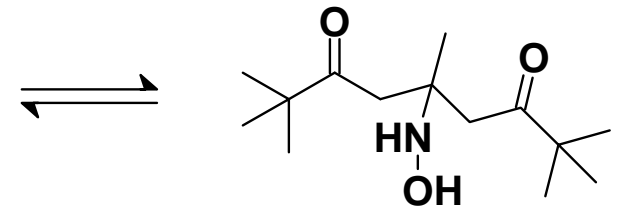

Or
1

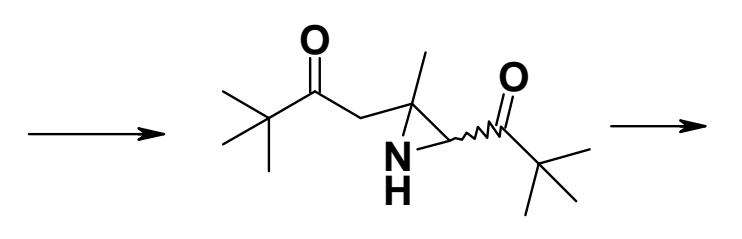

3

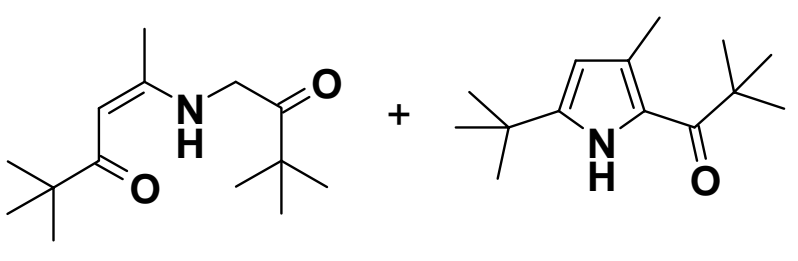

4<smiles>[R]C(=O)ONC(C)(CC(=O)C(C)(C)C)CC(=O)C(C)(C)C</smiles>

2 a: $R=M e \quad R$ b: $R=i P r$

\section{Scheme 1}

Examination of literature data showed that the transformations herein reported are unprecedented. The closest analogy was found to be the base-induced cyclization of $\beta$ alkoxyamino ketones obtained in turn by Michael addition of alkoxyamines to $\alpha$, $\beta$-unsaturated ketones. It gave $\alpha$-ketoaziridines in preparative yields for a large number of aryl or aryl-alkyl enones. $^{2-4}$

In the reaction performed with chalcone, subsequent isomerization of 2-benzoyl-3phenylaziridine to $\alpha$-aminochalcone has been reported. ${ }^{5}$ Depending on the nature of the base and the solvent, $\beta$-elimination in the primary Michael adduct giving $\beta$-aminochalcone was also found to occur. ${ }^{6}$ However, neither of these mechanisms would account for the enamine $\mathbf{4}$ and pyrrole 5 and this fact prompted us to investigate the mechanism of these transformations.

\section{Results}

Compounds 1, 2a and $\mathbf{2 b}$ were prepared starting from 2,6-di-tert-butyl-4-methylpyrylium as previously described. ${ }^{1}$

The acetyloxyamino derivative $\mathbf{2 a}$ was subjected to treatment with bases at ambient atmosphere under the following conditions:

(i) diluted aqueous sodium hydroxide, at reflux;

(ii) sodium methoxide in methanol, at room temperature;

(iii) sodium tert-amyloxide in benzene, at room temperature.

The conditions chosen encompassed a drastic change of the medium from protic polar solvents to the aprotic non-polar solvent benzene. Working in benzene required the replacement of the insoluble sodium methoxide with sodium tert-amyloxide, which has a good solubility in this solvent. The reaction was monitored by analytical tlc on silica gel until disappearance of the 
starting material. The products were separated by column chromatography on silica gel and characterized by elemental analysis, mass-spectrum and ${ }^{1} \mathrm{H}-,{ }^{13} \mathrm{C}-\mathrm{NMR}$ data (see Experimental part). The results are summarized in Table 1, the structure and the numbering of the compounds are given in Schemes 1 and 2.

tBuCOCH=C(Me) $\mathrm{CH}_{2} \mathrm{COtBu} \quad 6$

tBuCOCH=C(Me)NHCH=C(OMe)tBu 7

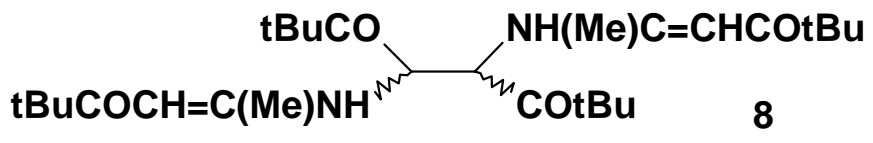

\section{Scheme 2}

Table 1. Yields in isolated products (\%) during the reaction of acyloxyamino derivatives $\mathbf{2 a}$ and 2b with bases

\begin{tabular}{|cc|c|c|c|c|c|c|c|c|c|}
\hline \multicolumn{2}{|c|}{$\begin{array}{c}\text { Entry } \\
\text { substrate }^{(i)}\end{array}$} & Conditions $^{(\text {ii })}$ & $\mathbf{1}$ & Z, E-3 & Z-4 & $\mathbf{7}$ & $\mathbf{5}$ & $\mathbf{8}$ & $\mathbf{6}$ & D $^{(i i i)}$ \\
\hline 1 & $\mathbf{2 a}$ & $\begin{array}{c}0.5 \mathrm{~N} \mathrm{NaOH}(\text { aq. }) \\
(1: 1), 2 \mathrm{~h}, \mathrm{reflux}\end{array}$ & 38.7 & - & 41.8 & - & 1.0 & - & 11.8 & - \\
\hline 2 & $\mathbf{2 a}$ & $\begin{array}{c}\mathrm{MeONa} / \mathrm{MeOH} \\
(1: 1), 1.5 \mathrm{~h}\end{array}$ & 67.0 & - & 10.3 & 1.3 & 7.7 & - & 5.2 & 1.0 \\
\hline 3 & $\mathbf{2 a}$ & $\begin{array}{c}t \mathrm{AmONa} / \mathrm{C}_{6} \mathrm{H}_{6} \\
(1: 1), 2 \mathrm{~h}\end{array}$ & 9.2 & 32.5 & 27.8 & - & 8.0 & 5.0 & - & 1.0 \\
\hline 4 & $\mathbf{2 a}$ & $\begin{array}{c}t \mathrm{AmONa} / \mathrm{C}_{6} \mathrm{H}_{6} \\
(1: 2), 2 \mathrm{~h}\end{array}$ & 9.6 & - & - & - & 11.3 & 19.5 & - & 16.0 \\
\hline 5 & $\mathbf{2 b}$ & $\begin{array}{c}\mathrm{MeONa} / \mathrm{MeOH} \\
(1: 1), 1.5 \mathrm{~h}\end{array}$ & 29.7 & - & 40.8 & 3.7 & 9.3 & - & 2.3 & 2.0 \\
\hline
\end{tabular}

(i) Concentration of the substrate: $0.10-0.15 \mathrm{M}$

(ii) Base/Solvent; the molar ratio substrate/base in brackets. Unless otherwise stated, room temperature.

(iii) Degradation products (unidentified).

Abbreviation: $t \mathrm{Am}=$ tert-amyl

The hydrolysis of $\mathbf{2 a}$ gave isoxazolidinol $\mathbf{1}$ and the rearrangement product $\mathbf{4}$ in $40 \%$ yield each, along with the pseudobase $\mathbf{6}$ of the starting pyrylium salt. (Table 1, entry 1).

In the reaction performed with one equivalent of sodium methoxide in methanol, the major product was isoxazolidinol 1 (67\% yield). The rearrangement product 4 was obtained in 10\% yield and was accompanied by its enol ether derivative 7 in $1 \%$ yield. We isolated also the pyrrole derivative 5 in $8 \%$ yield (entry 2 ).

A significant change in the nature and distribution of products was observed in the reaction with sodium tert-amyloxide in benzene. When working with one equivalent of base, the major 
products were the enamino diketone 4 (28\% yield) along with a cyclic isomer, the aziridine diketone 3 (33\% yield). The pyrrole 5 was obtained in the same yield as in entry 2 , whereas the yield in isoxazolidinol 1 was under $10 \%$. A surprising compound $\mathbf{8}$, actually a "dimeric" enamino diketone, was isolated in 5\% yield (entry 3 ).

When performing the reaction with two equivalents of sodium tert-amyloxide (entry 4 ), the yields in dimer $\mathbf{8}$ increased to $20 \%$ at the expense of aziridine 3 and enamino diketone $\mathbf{4}$, whereas the yields of isoxazolidinol 1 and pyrrole 5 remained almost the same. A considerable amount of degradation products was obtained (16\%, compared to $1 \%$ in entry 3$)$.

\section{Structure proofs and stereochemistry}

The structure proof for the rearrangement product 4 was the hydrolysis with aqueous hydrochloric acid, which gave pivaloyl acetone and 1-amino-3,3-dimethyl-2-butanone hydrochloride (see Experimental part).

Compound 4 was obtained as a single stereoisomer which, according to NOEDIF experiments, is the Z-form: irradiation of the $4-\mathrm{CH}$ signal at $\delta=5.2 \mathrm{ppm}$ increased the 5 -Me signal at $\delta=1.9 \mathrm{ppm}$.

The enol ether derivative 7 was identified by comparing its NMR data with those of the parent compound 4.

The aziridine 3 resulted as a mixture of E,Z-isomers in 20:80 ratio. Column chromatography on silica gel enabled the isolation of pure Z-3; a crystalline derivative with 3,5dinitrobenzoic acid was prepared for analytical purposes. For stereochemical assignment, the ${ }^{13} \mathrm{C}-\mathrm{NMR}$ chemical shifts in the diastereoisomeric pair were observed. The 2-Me signal in E-3 $(\delta=16.6 \mathrm{ppm})$ is upfield shifted compared to $Z-3(\delta=24.2 \mathrm{ppm})$ due to steric compression of the 3 -pivaloyl group. The same effect accounts for the upfield shift of the $2-\mathrm{CH}_{2}$ signal in Z-3 $(\delta=39.6 \mathrm{ppm})$ compared to $E-3(\delta=47.0 \mathrm{ppm})$. The assignment agrees with previously reported results in the $E, Z$ pair of 1-alkyl-2-aroyl-3-methylaziridines. ${ }^{7}$

The structure of the pyrrole derivative $\mathbf{5}$ was established on the basis of mass spectral and NMR data.

The dimer 8 resulted as two diastereoisomers (in 85:15 ratio) which could be separated by column chromatography on silica gel. The X-ray crystal structure of the major stereoisomer is displayed in Figure 1. It appears as achiral meso form and exhibits a $Z$ geometry at its $\mathrm{C}=\mathrm{C}$ double bond, as in the congeneric "monomer" Z-4. 


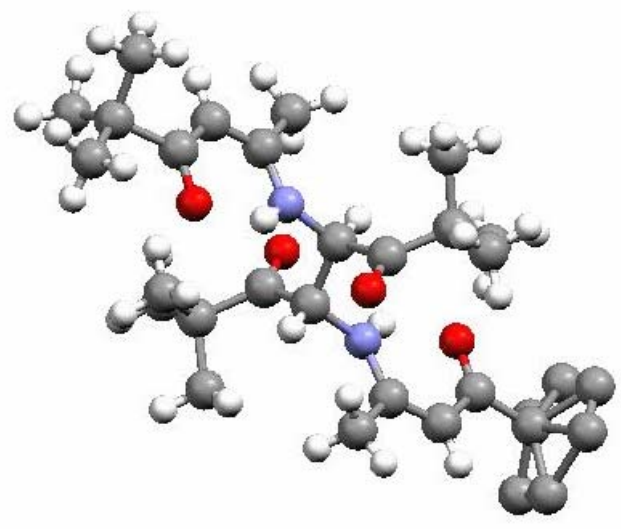

Figure 1. The X-ray structure of meso-8

The minor stereoisomer was assigned as the chiral $( \pm$ ) form; an alternative with the minor stereoisomer being the opposite $E$ form was ruled out since chemical shifts of 5-Me and 4-H are quite close in both isomers, indicating the same geometry of the $\mathrm{C}=\mathrm{C}$ double bond.

This assignment has been checked by chiral HPLC analysis of the two stereoisomers. The chiral isomer was partially resolved and was separated from the achiral meso isomer (see Experimental part).

\section{Discussion}

The results in Table 1 agree with the rearrangement of the 3-acyloxyamino-1,5-diketone derivative 2 into enamino diketone 4 occurring in two steps, through the intermediate aziridine diketone 3. As regards stereochemical outcome, the cyclization step gave both E, Z-3, whereas 4 resulted as single $Z$-isomer.

Further evidence for the occurrence of aziridine intermediate was obtained by an independent experiment in which a sample of E,Z-3 was treated with aqueous sodium hydroxide at room temperature. After $24 \mathrm{~h}$, we obtained Z-4 in 87\% yield and the pyrrole derivative 5 in 5\% yield. This result indicated aziridine $\mathbf{3}$ as common precursor for both $\mathbf{4}$ and $\mathbf{5}$.

The dimer $\mathbf{8}$ appeared only in the runs with sodium tert-amyloxide and the yield of this dimer increased when two instead of one equivalent of base was used, suggesting that $\mathbf{8}$ might result from 4 with excess base. This assumption has been checked by treating 4 with one equivalent of sodium tert-amyloxide in benzene for $5 \mathrm{~h}$ at ambient atmosphere and at room temperature. Separation by column chromatography gave dimer $\mathbf{8}$ in $50 \%$ yield along with the same degradation products as in runs 3 and $\mathbf{4}$ in $25 \%$ yield.

The origin of the enol ether 7 was similarly established by treating 4 with one equivalent of sodium methoxide in methanol. After $24 \mathrm{~h}$ at room temperature, enamino-diketone 4 was 
recovered in $40 \%$ yield along with the enol ether 7 in $20 \%$ yield and the same degradation products as in run 2 in $30 \%$ overall yield.

The experiments which established the origin of products are summarized in Scheme 3.

$$
\begin{gathered}
E, Z-3 \stackrel{\text { aq. } \mathrm{NaOH}}{\longrightarrow} Z-4+5 \\
7 \text { + degrad. cpds } \underset{\mathrm{MeOH}}{\stackrel{\mathrm{MeONa}}{\longleftarrow}-4} \stackrel{\mathrm{t}-\mathrm{AmONa}}{\text { Benzene }} 8 \text { + degrad. cpds }
\end{gathered}
$$

\section{Scheme 3}

In conclusion, among the products in Table 1 only isoxazolidinol $\mathbf{1}$ and aziridine $\mathbf{3}$ appear as primary products from the acetyloxyamino-diketone $\mathbf{2 a}$. The enamine $\mathbf{4}$ and the pyrrole $\mathbf{5}$ originated from aziridine $\mathbf{3}$ whereas further transformation of $\mathbf{4}$ under the reaction conditions gave the dimer $\mathbf{8}$ and the enol ether 7. The formation of the pseudobase $\mathbf{6}$ may be reasonably explained by a retro-Michael reaction of isoxazolidinol 1.

The following competing paths for the formation of the primary products are proposed (Scheme 4):

(i) proton release from the activated methylene in $\mathbf{2 a}$ and cyclization with acetate ion as leaving group, which gives the aziridine $\mathbf{3}$;

(ii) displacement of methyl acetate following the nucleophilic attack of the methoxide ion on the acetyl moiety, which gives isoxazolidinol 1.

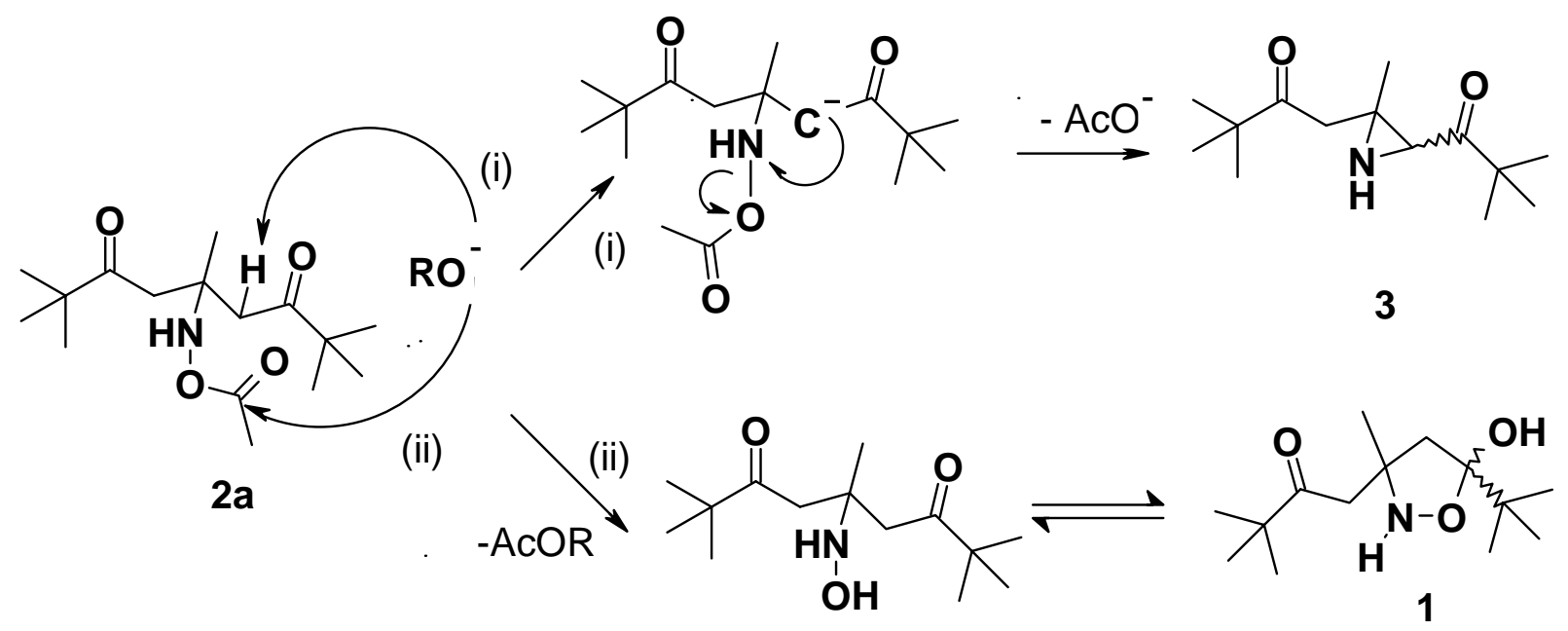

Scheme 4 
The tert-amyloxide ion, a poor nucleophile due to its bulkiness, directs the reaction on path (i) and the cyclization product prevails, whereas with the methoxide ion, a good nucleophile, the reaction follows mainly path (ii) and isoxazolidinol $\mathbf{1}$ is the major product.

Should this explanation be correct, a more crowded tetrahedral intermediate in path (ii) should also disfavour it. Indeed, when treating the isobutyrate derivative $\mathbf{2 b}$ with an equivalent of sodium methoxide (Table 1, entry 5 to be compared with entry 2), the yield in isoxazolidinol 1 decreased from $67 \%$ to $30 \%$ and that of enamino-diketone 4 (originating from 3 ) increased from $10 \%$ to $40 \%$, a result in full agreement with the above reasoning. The mechanism in Scheme 5 accounts for the formation of $\mathbf{4}$ and $\mathbf{5}$ from aziridine $\mathbf{3}$ under basic catalysis.

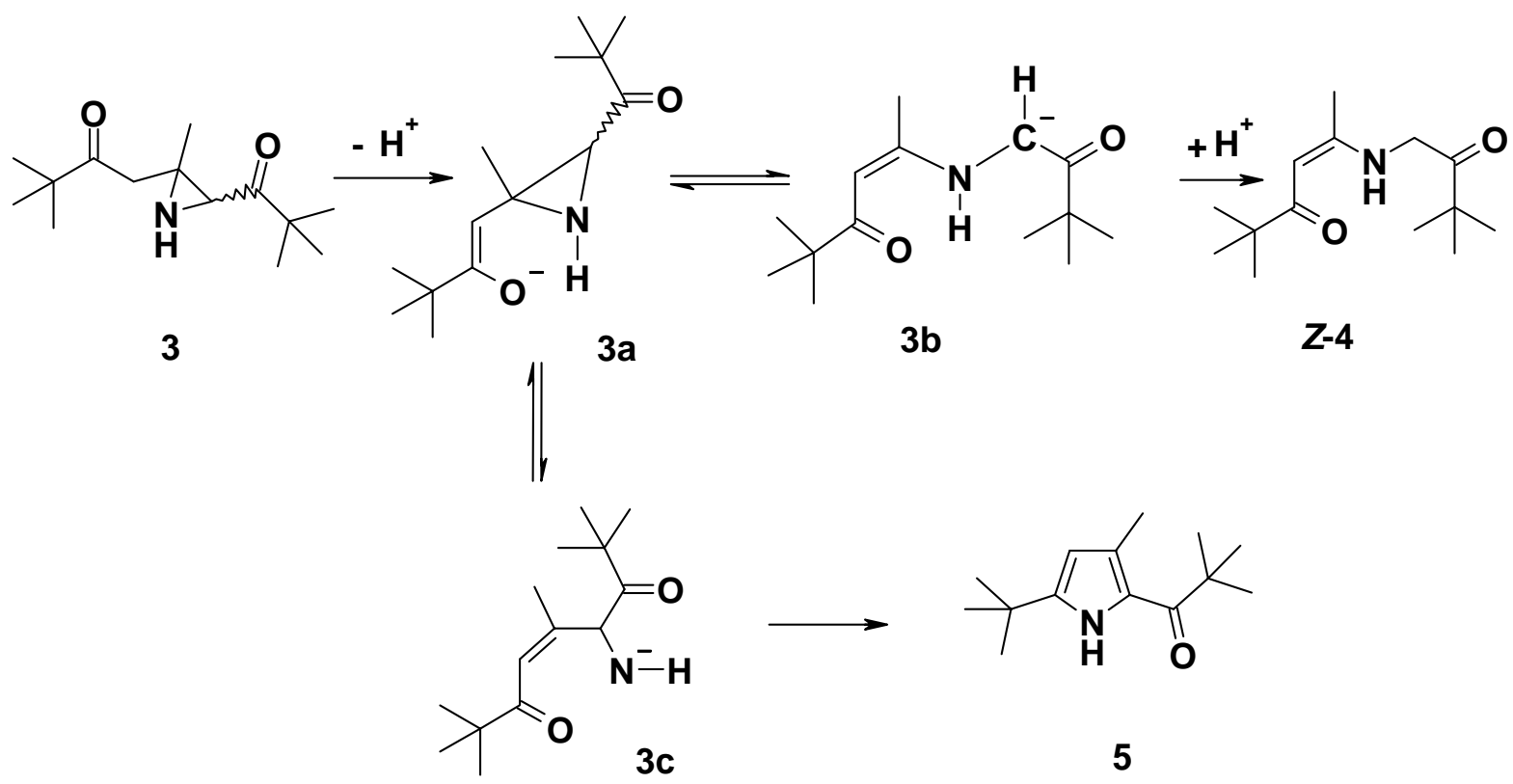

\section{Scheme 5}

Deprotonation occurs in the activated side-chain methylene of $\mathbf{3}$, prevailing over deprotonation in the endocyclic methine since the former gives a more stable enolate (3a). The ring-opening with $\mathrm{C}, \mathrm{C}$ bond breaking in $\mathbf{3 a}$ gives $\mathbf{3 b}$ which leads by protonation to the rearrangement product $\mathbf{4}$. The possible hydrogen bonding involving $\mathrm{NH}$ in $\mathbf{3 b}$ enhances the intermediate stability and explains nicely the $Z$ stereochemistry of 4 .

The occurrence of the minor product 5 may be explained by $\mathrm{C}, \mathrm{N}$ bond breaking in 3a giving the amide ion $\mathbf{3 c}$, a less favored path since leads to a highly energetic intermediate but releasing the ring strain as well. Internal addition in $\mathbf{3 c}$ followed by dehydration with aromatization as driving force gives the pyrrole derivative $\mathbf{5}$.

There still remains to be explained the formation of the dimer $\mathbf{8}$ in the reaction performed with sodium tert-amyloxide compared to that with sodium methoxide in methanol, which gave the enol ether 7 without any trace of dimer. A tentative explanation is presented in Scheme 6. 


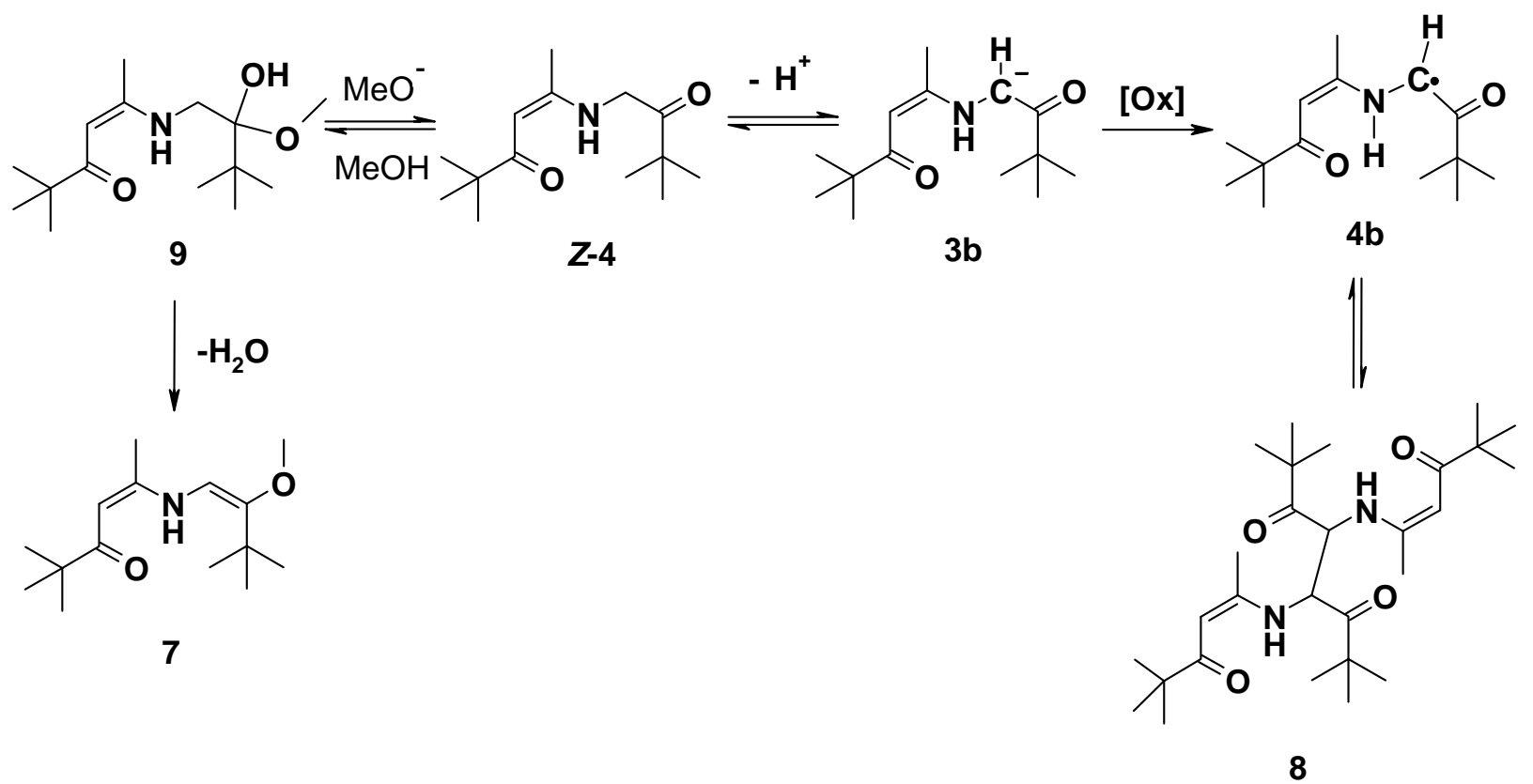

\section{Scheme 6}

Two equilibria may be established under the action of the alkoxide on the enamino diketone 4: formation of a hemiketal $\mathbf{9}$ and deprotonation of the activated methylene giving $\mathbf{3 b}$. With sodium methoxide and a large excess of methanol, the first equilibrium prevails and directs the reaction towards 7 by irreversible dehydration of the hemiketal 9 . Conversely, with the bulky, poorly nucleophilic tert-amyloxide only the second equilibrium comes into play. The oxidation of the carbanion, presumably with atmospheric oxygen, leads to a radical $\mathbf{4 b}$ stabilized by the capto-dative effect ${ }^{8-11}$; dimerization of $\mathbf{4 b}$ gives 8 .

Finally, a brief comment in connection with thermal or photochemical transformations of 2,3-dihydroisoxazoles ${ }^{12}$ is made. The key intermediates in such transformations are 2acylaziridines. The mechanism involves aziridine-ring opening to azomethine ylides (isolable in some cases) $)^{13}$, which undergo further reactions with formation of pyrroles, ${ }^{14-17}$ 2,3dihydrooxazoles $^{18}$ or may dimerize to piperazine derivatives. An enamine intermediate was formulated for explaining the origin of pyrroles, arising from 1,4-hydrogen shift (probably concerted) in the betaine. This intermediate is quite similar to enamine 4 in this paper, which formally resulted also through $\mathrm{C}, \mathrm{C}$ bond-breaking in 3 and a 1,4-hydrogen shift, but occurring stepwise under base catalysis (see Scheme 5). Interestingly, under the conditions of the present work enamine 4 is an isolable compound and does not evolve into a pyrrole derivative, as in thermal processes. Indeed, the pyrrole 5 isolated in this work definitely resulted through $\mathrm{C}, \mathrm{N}$ bond-breaking in $\mathbf{3}$ (cyclocondensation of $\mathbf{4}$ would provide a regioisomer of $\mathbf{5}$ ). 


\section{Conclusions}

The 3-acyloxyamino-1,5-diketones 2 exhibited under basic conditions a versatile reactivity: cyclization giving aziridine $\mathbf{3}$ competes with deacylation to the parent 5-isoxazolidinol $\mathbf{1}$. The influence of the base nucleophilicity and of the acyl radical size was discussed. It was concluded that poor-nucleophilic bases (such as sodium tert-amyloxide) promote aziridination. Based on these results, we propose an alternative preparation of $\alpha$-ketoaziridines from $\alpha, \beta$-unsaturated ketones by replacing alkoxyamines (as in references 2-4) with hydroxylamine, a more common and cheaper reagent. The work on this preparation is in progress.

Facile aziridine ring-opening in $\mathbf{3}$ was found to occur under basic conditions, prevailingly with $\mathrm{C}, \mathrm{C}$ bond breaking and giving isomeric enamine 4 . A minor path occurring with $\mathrm{C}, \mathrm{N}$ bond breaking gave a ring-enlargement product, pyrrole 5. Formation of the dimeric enamine 8 with open structure should be noticed. So far, only cyclodimers (regioisomers of piperazine derivatives) ${ }^{12,19}$ have been reported in ring-opening reactions of aziridines.

\section{Experimental Section}

General Procedures. Reagents and solvents. Sodium tert-amyloxide was prepared as described $^{20}$ and was titrated with $0.1 \mathrm{~N}$ hydrochloric acid using phenolphthalein as indicator. In the runs, $0.35 \mathrm{M}$ stock-solution in benzene was used. The sodium methoxide in methanol $(0.34$ M) was titrated by the same method.

Silica gel 60 (Fluka) was used for column chromatography. For analytical tlc, sheets of silica gel 60 F 254 coated on aluminium (Merck) were used.

Elution was performed with diethyl ether (EE) freshly distilled on lithium aluminium hydride and with petroleum ether (PE ; b.p. range $35-55^{\circ} \mathrm{C}$ ). The reported $\mathrm{R}_{\mathrm{f}}$ values were measured in 1:1 (v) EE/PE mixture.

In chiral HPLC analysis, n-hexane and 2-propanol HPLC grade from SDS (Peypin, France) were used. The solvents were degassed and filtered on a Millipore membrane $0.45 \mu \mathrm{m}$ before use.

Instrumentation. Melting points were determined on a Boetius hot stage and are uncorrected. The NMR spectra were recorded on a Bruker Avance instrument $\left(400 \mathrm{MHz}\right.$ for ${ }^{1} \mathrm{H}, 100 \mathrm{MHz}$ for ${ }^{13} \mathrm{C}$ ), in $\mathrm{CDCl}_{3}$ solution. The $\delta(\mathrm{ppm})$ values were measured from internal TMS, the coupling constants $J$ are given in Hz. The assignment was rendered unambiguous through 2D (HMQC, HMBC) techniques. Mass spectra were recorded with a Carlo-Erba QMD1000 instrument.

Chiral HPLC analyses were performed with an unit composed of a Merck D-7000 system manager, Merck-Lachrom L-7100 pump, Merck-Lachrom L-7360 oven, Merck-Lachrom L-7400 UV-detector, and Jasco OR-1590 polarimeter on Whelk-O1 (S,S) $(250 * 4.6 \mathrm{~mm}, 5 \mu \mathrm{m})$, available from Regis (Morton Grove). 
CCDC-259682 contains the supplementary crystallographic data for this paper. These data can be obtained free of charge at www.ccdc.cam.ac.uk/conts/retrieving.html [or from the Cambridge Crystallographic Data Center, 12 Union Road, Cambridge CB2 1EZ, UK; Fax: (internat.) +44-1223/336-033; E-mail: deposit@ccdc.cam.ac.uk].

Reaction of derivative 2a with bases (run 3, Table 1). Acetyloxyamino derivative $\mathbf{2 a}^{1}$ (502 $\mathrm{mg}, 1.68 \mathrm{mmol}$ ) dissolved in $5 \mathrm{~mL}$ benzene was treated dropwise under magnetic stirring with $0.35 \mathrm{M}$ sodium tert-amyloxide solution in benzene $(4.8 \mathrm{~mL}, 1.68 \mathrm{mmol})$ over 5 minutes. The solution became cloudy and a slight heating was observed. Stirring continued for $2 \mathrm{hrs,} \mathrm{then} 5$ $\mathrm{mL}$ water was added and the phases were separated. The benzene layer was washed with water, then with saturated sodium carbonate solution and dried over anhydrous sodium sulfate. After evaporating the solvent under reduced pressure, the crude product (420 mg) was chromatographed on $4.5 \mathrm{~g}$ silica gel, eluting with gradient EE/PE mixtures (from 5\% to $100 \% \mathrm{v}$ EE). In the elution order, the following fractions were collected: pyrrole 5 (30 mg, 8\% yield), "dimer" 8 (20 mg, 5\% yield), enamine 4 (112 mg, 27.8\% yield), aziridine 3 (130 mg, 32.5\% yield) and 5-isoxazolidinol 1 (40 mg, 9.2\% yield).

The other runs in Table 1 were similarly performed.

(Z)1-[3'-(2"2"-Dimethyl-propionyl)-2'-methyl-aziridin-2'-yl]-3,3-dimethyl-butan-2-one (3). $\mathrm{R}_{\mathrm{f}}$ $=0.12,1: 1(\mathrm{v})$ EE/PE. ${ }^{1} \mathrm{H}-\mathrm{NMR}: \delta=1.09$ (s, 9H, Me $\left.{ }_{3} \mathrm{C}-3\right), 1.22$ (s, 9H, Me $\left.\mathbf{M}_{3} \mathrm{C}-2^{\prime \prime}\right), 1.32$ (s, 3H, 2'$\mathrm{Me}), 2.65\left(\mathrm{~d}, \mathrm{~J}_{\mathrm{AB}}=18.0 \mathrm{~Hz}, 1-\mathrm{H}_{\mathrm{A}}\right), 2.87\left(\mathrm{~d}, \mathrm{~J}_{\mathrm{BA}}=18.0 \mathrm{~Hz}, 1-\mathrm{H}_{\mathrm{B}}\right), 3.00(\mathrm{~s}, 1 \mathrm{H}, 3-\mathrm{H}) \mathrm{ppm}$.

${ }^{13} \mathrm{C}-\mathrm{NMR}: \delta=24.2$ (Me C-2 ), $26.3\left(\mathbf{M e}_{3} \mathrm{C}-2^{\prime \prime}\right), 26.3\left(\mathbf{M e}_{3} \mathrm{C}-3\right), 39.6$ (C-1), 42.5 (C-2'), 43.8 (C$\left.2^{\prime \prime}\right), 44.1$ (C-3), 44.2 (C-3'), 212.5 (C-1"), 212.9 (C-2) ppm.

Salt with 3,5-dinitrobenzoic acid. On mixing ethereal solutions of aziridine Z-3 and 3,5dinitrobenzoic acid, slow precipitation occurred. Recrystallization from ethanol gave colourless crystals, m.p. $127-9^{\circ} \mathrm{C} .{ }^{1} \mathrm{H}-\mathrm{NMR}: \delta=1.10(\mathrm{~s}, 9 \mathrm{H}), 1.27(\mathrm{~s}, 9 \mathrm{H}), 1.44(\mathrm{~s}, 3 \mathrm{H}), 2.74(\mathrm{~d}, \mathrm{~J}=18.0 \mathrm{~Hz}$, 1H), 2.94 (d, J=18.0 Hz, $1 \mathrm{H}), 3.45$ (s, 1H); 6.1 (brd, 2H), 9.15-9.25 (m, 3H) ppm. ${ }^{13} \mathrm{C}-\mathrm{NMR}$ : $\delta=22.4,25.9,26.0,38.8,43.2,43.4,43.8,43.9,121.7,129.5,135.5,148.3,164.8,210.6,211.9$ ppm. $\mathrm{C}_{21} \mathrm{H}_{29} \mathrm{~N}_{3} \mathrm{O}_{8}$ (451.5): calc. C 55.87, H 6,47, N 9.31; found C 55.84, H 6.37, N 9.29\%.

(E)1-[3'-(2",2"-Dimethyl-propionyl)-2'-methyl-aziridin-2'-yl]-3,3-dimethyl-butan-2-one (3). $\mathrm{R}_{\mathrm{f}}=0.17,1: 1(\mathrm{v})$ EE/PE. ${ }^{1} \mathrm{H}-\mathrm{NMR}: \delta=1.14$ (s, 12H, Me ${ }_{3} \mathrm{C}-3$ and $2^{\prime}-\mathrm{Me}$ ), 1.26 (s, 9H, Me $\left.{ }_{3} \mathrm{C}-2^{\prime \prime}\right)$, $2.40\left(\mathrm{~d}, \mathrm{~J}_{\mathrm{AB}}=18.0 \mathrm{~Hz}, 1 \mathrm{H}, \mathrm{H}_{\mathrm{A}} \mathrm{C}-1\right), 2.94(\mathrm{~s}, 1 \mathrm{H}, 3-\mathrm{H}) .3 .11\left(\mathrm{~d}, \mathrm{~J}_{\mathrm{BA}}=18.0 \mathrm{~Hz}, 1 \mathrm{H}, \mathrm{H}_{\mathrm{B}} \mathrm{C}-1\right)$ ppm.

${ }^{13} \mathrm{C}-\mathrm{NMR}: \delta=16.6$ (Me C-2'), 26.1 (Me $\left.\mathrm{C}_{3} 2^{\prime \prime}\right), 26.2$ (Me $\left.\mathrm{C}-3\right) .42 .3$ (C-2'), 43.6 (C-2"), 44.0 (C3), 44.9 (C-3'), 47.0 (C-1), 211.3 (C-1"), 213.2 (C-2) ppm.

(Z) 5-(3',3'-Dimethyl-2'-oxo-butylamino)-2,2-dimethyl-hex-4-en-3-one)(4).Colourless crystals, m.p. $60-67^{\circ} \mathrm{C} ; \mathrm{R}_{\mathrm{f}}=0.27,1: 1(\mathrm{v}) \mathrm{EE} / \mathrm{PE} .{ }^{1} \mathrm{H}-\mathrm{NMR}: \delta=1.13\left(\mathrm{~s}, 9 \mathrm{H}, \mathbf{M e}_{3} \mathrm{C}-2\right), 1.18\left(\mathrm{~s}, 9 \mathrm{H}, \mathbf{M e}_{3} \mathrm{C}-3^{\prime}\right)$, 1.89(s, 3H, H $\left.{ }_{3} \mathrm{C}-6\right), 4.23\left(\mathrm{~d}, \mathrm{~J}=5.4 \mathrm{~Hz}, 2 \mathrm{H}, \mathrm{H}_{2} \mathrm{C}-1^{\prime}\right), 5.22(\mathrm{~s}, 1 \mathrm{H}, \mathrm{HC}-4), 11.1(\mathrm{brd}, 1 \mathrm{H}, \mathrm{NH}) \mathrm{ppm}$.

${ }^{13} \mathrm{C}-\mathrm{NMR}: \delta=19.7(\mathrm{C}-6), 26.4\left(\mathbf{M e}_{3} \mathrm{C}-3^{\prime}\right), 27.9\left(\mathbf{M e}_{3} \mathrm{C}-2\right), 41.5(\mathrm{C}-2), 43.1\left(\mathrm{C}-3{ }^{\prime}\right), 47.5\left(\mathrm{C}-1^{\prime}\right), 91.5(\mathrm{C}-$ 4), 162.3(C-5), 204.4(C-3), 208.7(C-2') ppm. MS: m/z (\%)= 239(6) [ $\left.\mathrm{M}^{+}\right], 182(100)\left[\mathrm{M}^{+}-\mathrm{C}_{4} \mathrm{H}_{9}\right]$, 154(42), 124(37), 57(76). 
Hydrolysis of Z-4. Hydrochloric acid $0.1 \mathrm{~N}$ (4.6 mL) was added to enamine 4 (110mg, 0.46 $\mathrm{mmol}$ ) dissolved in $5 \mathrm{~mL}$ diethyl ether and the mixture was kept under vigorous magnetic stirring for two hours at room temperature. The ethereal layer was washed with saturated sodium carbonate then with brine and evaporated under reduced pressure. The residue was chromatographed on $0.8 \mathrm{~g}$ silica gel, collecting with EE/PE $(5 \% \mathrm{v})$ pivaloylacetone $(45 \mathrm{mg}, 86 \%$ yield) then $21 \mathrm{mg}$ unreacted enamine 4 with EE/PE (30\%v). From the aqueous phase, aminobutanone hydrochloride crystallized on slow air-evaporation (44 mg, 78\% yield).

5,5-Dimethyl-hexane-2,4-dione (pivaloylacetone, keto tautomer, $12 \%$ in $\mathrm{CDCl}_{3}$ ). ${ }^{1} \mathrm{H}-\mathrm{NMR}$ $\delta=1.18(\mathrm{~s}, 9 \mathrm{H}), 2.19(\mathrm{~s}, 3 \mathrm{H}), 3.61(\mathrm{~s}, 2 \mathrm{H}) \mathrm{ppm}$.

2-Hydroxy-5,5-dimethyl-hex-2-en-4-one (enol tautomer, $88 \%$ in $\mathrm{CDCl}_{3}$ ). ${ }^{1} \mathrm{H}-\mathrm{NMR}$ : $\delta=1.12(\mathrm{~s}, 9 \mathrm{H}), 2.04(\mathrm{~s}, 3 \mathrm{H}), 5.57(\mathrm{~s}, 1 \mathrm{H}) \mathrm{ppm}$. The chemical shifts and keto/enol ratio are in very good agreement with literature data ${ }^{21-23} . \mathrm{MS}: \mathrm{m} / \mathrm{z}(\%)=142(31)\left[\mathrm{M}^{+}\right], 85(100)\left[\mathrm{M}^{+}-\mathrm{C}_{4} \mathrm{H}_{9}\right], 57$ (15) $\left[\mathrm{C}_{4} \mathrm{H}_{9}^{+}\right], 43$ (30) $\left[\mathrm{CH}_{3} \mathrm{CO}^{+}\right]$

1-Amino-3,3-dimethyl-butan-2-one, hydrochloride. Colourless crystals, m.p. $192-6^{\circ} \mathrm{C}$ (lit. $^{24}$ m.p. 199-200 $\left.{ }^{\circ} \mathrm{C}\right) .{ }^{1} \mathrm{H}-\mathrm{NMR}: \delta=1.18(\mathrm{~s}, 9 \mathrm{H}), 4.30(\mathrm{~s}, 2 \mathrm{H}), 8.26\left(\mathrm{brd}, 3 \mathrm{H}, \mathrm{NH}_{3}{ }^{+}\right)$ppm. ${ }^{13} \mathrm{C}-\mathrm{NMR}$ : 26.0, 43.0, 44.2, $208.9 \mathrm{ppm}$.

1-(5'-tert-Butyl-3'-methyl-1' $\boldsymbol{H}$-pyrrol-2'-yl)-2,2-dimethyl-propan-1-one (5). $\mathrm{R}_{\mathrm{f}}=0.66,1: 1(\mathrm{v})$ EE/PE. ${ }^{1} \mathrm{H}-\mathrm{NMR}: \delta=1.30\left(\mathrm{~s}, 9 \mathrm{H}, \mathbf{M e}_{3} \mathrm{C} \mathrm{C}-5^{\prime}\right), 1.35\left(\mathrm{~s}, 9 \mathrm{H}, \mathbf{M e}_{3} \mathrm{C}-2\right), 2.40\left(\mathrm{~s}, 3 \mathrm{H}, 3^{\prime}-\mathrm{Me}\right), 5.88(\mathrm{brd}$ s, 4'-H), 8.75 (brd s, 1H, NH) ppm. ${ }^{13} \mathrm{C}-\mathrm{NMR}: \delta=15.7$ (3'-Me), $27.6\left(\mathbf{M e}_{3} \mathrm{C}-2\right), 30.0\left(\mathbf{M e}_{3} \mathrm{C} \mathrm{C}-\right.$ 5'), $31.4\left(\mathrm{Me}_{3} \mathrm{C} \mathrm{C}-5^{\prime}\right), 42.0$ (C-2), 109.1 (C-4'), 125.6 (C-2'), 128.3 (C-3'), 145.7 (C-5'), 195.4 (C-1) ppm. MS: m/z (\%)=221 (23) $\left[\mathrm{M}^{+}\right], 164(100)\left[\mathrm{M}^{+}-\mathrm{C}_{4} \mathrm{H}_{9}\right], 121(21)$.

"meso"2,2,7,7-Tetramethyl-4,5-bis-(1,4,4-trimethyl-3-oxo-pent-1-enyl-amino)-octane-3,6dione (8). Colourless crystals, m.p. $252-3^{\circ} \mathrm{C}, \mathrm{R}_{\mathrm{f}}=0.64,1: 1(\mathrm{v}) \mathrm{EE} / \mathrm{PE} .{ }^{1} \mathrm{H}-\mathrm{NMR}: \delta=1.06$ (s, 9H), 1.07 (s, 9H), 1.93 (s, 3H), 5.03 (d, J=8 Hz, 1H), 5.08 (s, 1H), 11.03 (d, J=8 Hz, $1 \mathrm{H})$ ppm.

${ }^{13} \mathrm{C}-\mathrm{NMR}: \delta=19.0,25.4,27.6,41.5,44.4,56.2,92.9,160.5,204.8,211.4$ ppm. Elemental analysis : $\mathrm{C}_{14} \mathrm{H}_{24} \mathrm{NO}_{2}$ (238.3): calc. C 70.55, $\mathrm{H}$ 10.15, N 5.88; found : C 70.21, H 9.79, N 5.88\%.

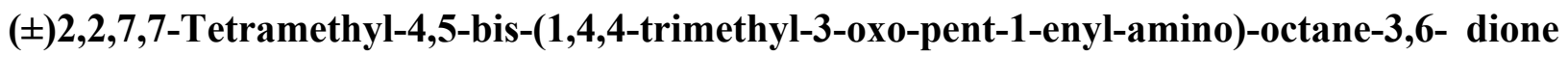
(8). ${ }^{1} \mathrm{H}-\mathrm{NMR}: \delta=1.11(\mathrm{~s}, 9 \mathrm{H}), 1.16(\mathrm{~s}, 9 \mathrm{H}), 1.89(\mathrm{~s}, 3 \mathrm{H}), 4.93(\mathrm{~d}, \mathrm{~J}=8 \mathrm{~Hz}, 1 \mathrm{H}), 5.15(\mathrm{~s}, 1 \mathrm{H})$, $10.92(\mathrm{~d}, \mathrm{~J}=8 \mathrm{~Hz}, 1 \mathrm{H}) \mathrm{ppm} .{ }^{13} \mathrm{C}-\mathrm{NMR}: \delta=19.2,26.9,27.7,41.6,44.2,58.4,92.9,162.8,205.2$, $211.5 \mathrm{ppm}$. The chiral HPLC analysis of the "meso" $\mathbf{8}$ and $( \pm) \mathbf{8}$ was performed under the following conditions: Whelk-O1 (S,S) column, with hexane/2-propanol (96/4) as mobile phase, at $1 \mathrm{~mL} / \mathrm{min}, 25^{\circ} \mathrm{C}$, with $\mathrm{UV}$ detection at $254 \mathrm{~nm}$ and on-line polarimeter. The chiral compound was partially resolved: polarimeter retention time $\mathrm{R}_{\mathrm{t}}(+)=4.54 \mathrm{~min}, \mathrm{k}(+)=0.28, \mathrm{R}_{\mathrm{t}}(-)=4.74 \mathrm{~min}$, $\mathrm{k}(-)=0.33$ and was separated from the achiral meso compound: UV detector retention time $\mathrm{R}_{\mathrm{t}}($ meso $)=5.23 \mathrm{~min}, \mathrm{k}($ meso $)=0.73$.

(Z) 2, 2, 5, 8, 8 - Pentamethyl-non-4-en-3, 7-dione (6): $\mathrm{R}_{\mathrm{f}}=0.62,1: 1(\mathrm{v}) \mathrm{EE} / \mathrm{PE} .{ }^{1} \mathrm{H}-\mathrm{NMR}: \delta=$ $1.13(\mathrm{~s}, 9 \mathrm{H}), 1.20(\mathrm{~s}, 9 \mathrm{H}), 1.90(\mathrm{~s}, 3 \mathrm{H}), 3.92(\mathrm{~s}, 2 \mathrm{H}), 6.48(\mathrm{~s}, 1 \mathrm{H}) \mathrm{ppm} .{ }^{13} \mathrm{C}-\mathrm{NMR}: \delta=26.5,26.6$, 26.7, 41.9, 43.6, 44.5, 122.0, 151.6, 205.7, $212.2 \mathrm{ppm}$. 
(E) 2, 2, 5, 8, 8 - Pentamethyl-non-4-en-3, 7-dione (6). $\mathrm{R}_{\mathrm{f}}=0.62,1: 1(\mathrm{v}) \mathrm{EE} / \mathrm{PE} .{ }^{1} \mathrm{H}-\mathrm{NMR}: \delta=$ $1.14(\mathrm{~s}, 9 \mathrm{H}), 1.18(\mathrm{~s}, 9 \mathrm{H}), 2.07(\mathrm{~s}, 3 \mathrm{H}), 3.34(\mathrm{~s}, 2 \mathrm{H}), 6.28(\mathrm{~s}, 1 \mathrm{H}) \mathrm{ppm} .{ }^{13} \mathrm{C}-\mathrm{NMR}: \delta=19.9,26.3$, 26.5, 43.7, 44.5, 48.4, 123.1, 151.0, 205.7, $212.0 \mathrm{ppm}$.

5-(2-Methoxy-3,3-dimethyl-but-1-enylamino)- 2,2-dimethyl-hex-4-en-3-one (7). $R_{f}=0.43$, 1:1(v) EE/PE. ${ }^{1} \mathrm{H}-\mathrm{NMR}: \delta=1.15$ (s, 9H), 1.23 (s, 9H), 2.06 (s, 3H), 3.15 (s, 3H), $5.31(\mathrm{~s}, 1 \mathrm{H})$, $5.55(\mathrm{~d}, \mathrm{~J}=8.8 \mathrm{~Hz}, 1 \mathrm{H}), 11.1(\mathrm{~d}, \mathrm{~J}=8.8 \mathrm{~Hz}, 1 \mathrm{H}) \mathrm{ppm} .{ }^{13} \mathrm{C}-\mathrm{NMR}: \delta=19.4,26.4,27.6,42.1,43.1$, $51.2,79.3,94.3,160.0,205.6,206.5 \mathrm{ppm}$

\section{Acknowledgments}

Thanks are due to Dr. Petru Filip for recording the mass-spectra.

\section{References}

1. (a) Uncuta, C.; Tudose, A.; Caproiu, M. T.; Udrea, S.; Roussel, C. Eur. J. Org. Chem. 2003, 1789. (b) Uncuta, C.; Tudose, A.; Caproiu, M. T.; Plaveti, M.; Kakou-Yao, R. Tetrahedron 1999, 55, 15011.

2. Nagel, D. L.; Woller, P. B.; Cromwell, N. H. J. Org. Chem. 1971, 36, 3911.

3. Coldham, I.; Collis, A. J.; Mould, R. J.; Rathmell, R. E. J. Chem. Soc. Perkin Trans. 1 1995, 2739.

4. Sugihara, H.; Daikai, K.; Jin, X. L.; Furuno, H.; Inanaga, J. Tetrahedron Letters 2002, 43, 2735.

5. (a) Reichel, L.; Pritze, P. Liebigs Ann. Chem. 1974, 120. (b) Blatt, A. H. J. Am. Chem. Soc. 1939, 61, 3494. (c) Cromwell, N. H.; Barker, N. G.; Wankel, R. A.; Vanderhorst, P. J.; Olson, F. W.; Anglin Jr., J. H. J. Am. Chem. Soc. 1951, 73, 1044.

6. Seko, S.; Tani, N. Tetrahedron Letters 1998, 39, 8117.

7. Tarburton, P.; Kingsbury, C. A.; Sopchick, A. E.; Cromwell, N. H. J. Org. Chem. 1978, 43, 1350 .

8. Viehe, H. G.; Janousek, Z.; Merenyi, R.; Stella, L. Acc. Chem. Res. 1985, 18, 148.

9. Viehe, H. G.; Merenyi, R.; Stella, L.; Janousek, Z. Angew. Chem. 1979, 91, 982-997; Angew. Chem. Int. Ed. 1979, 18, 917.

10. Sustmann, R.; Korth, H. -G. Adv. Phys. Org. Chem. 1990, 26, 131.

11. Stella, L.; Harvey, J. N. "Synthetic Utility of the Captodative Effect" In Radicals in Organic Synthesis Renaud, P.; Sibi, M. P. Eds., 2001, Wiley VCH: Weinheim, Ch. 3.3.

12. Review: Freeman, J. P. Chem.Rev. 1983, 83, 241-261.

13. Lopez-Calle, E.; Keller, M.; Eberbach, W. Eur. J. Org. Chem. 2003, 1438 and references therein.

14. Adachi, I.; Harada, K.; Kano, H. Tet. Letters 1969, 4875. 
15. Schmidt, G.; Stracke, H.-U.; Winterfeldt, E. Chem. Ber. 1970, 103, 3196.

16. Padwa, A.; Dean, D.; Oine, T. J. Am. Chem. Soc. 1975, 97, 2822.

17. Yu, Y.; Ohno, M.; Eguchi, S. Tetrahedron 1993, 49, 823.

18. Baldwin, J. E.; Pudussery, R. G.; Qureshi, A. K.; Sklarz, B. J. Am. Chem. Soc. 1968, 90, 5325.

19. Katritzky, A. R.; Wang, Z.; Lang, H.; Steel, P. J. Heterocyclic Communications 1996, 2, 109.

20. Conia, J. -M. Bull. Soc. Chim. France 1950, 533.

21. Bassetti, M.; Cerichelli, G.; Floris, B. Gazz. Chim. Ital. 1986, 116, 579.

22. Bassetti, M.; Cerichelli, G.; Floris, B. Tetrahedron 1988, 44, 2997.

23. Fujii, H.; Yoshimura, T.; Kamada, H. Tetrahedron Letters 1997, 38, 1427.

24. Chiba, T.; Sakagami, H.; Murata, M.; Okimoto, M. J. Org. Chem. 1995, 60, 6764. 